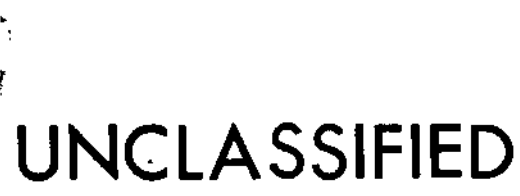

RECORDS ADMINISTRATION

$\mathrm{R} 0138652$
$\sqrt{D P}-64$

Physics

AEC Research and Development Report

NEUTRON ENERGY SPECTRA IN WATER

by

H. D. Brown

Theoretical Physics Division

February 1956

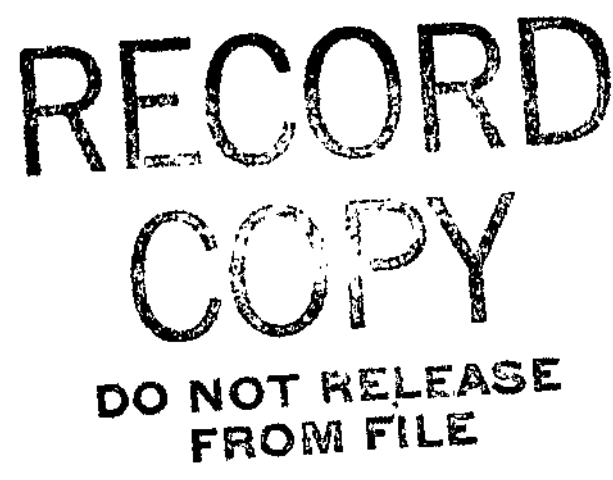

E. I. du Pont de Nemours \& Co.

Explosives Department - Atomic Energy Division

Technical Division - Savannah River Laboratory 


\section{NEUTRON ENERGY SPECTRA IN WATER}

\section{by}

H. Dean Brown

Theoretical Physics Division

February 1956

E. I. du Pont de Nemours \& Co.

Explosives Department - Atomic Energy Division Technical Division - Savannah River Laboratory

Printed for

The United States Atomic Energy Commission Contract AT $(07-2)-1$

Price $\$ 0.20 \quad$ Avaliable from the office of Technical Services, Department of Commerce, Washington 25, D. C. 


\section{ABSTRACT}

Neutron energy spectra are computed for homogeneous reactors moderated by heavy water or by light water. The effects of chemical binding, of moderator motion, and of neutron absorption are considered. A formula is given for the temperature of the thermal region of the spectrum as a function of absorption and moderator temperature.

External Distribution according to TID-4500(10th Ed.) 
INTRODUCTION

$\underline{\text { Page }}$

SUMMARY

DISCUSSION

Physical Model

Numerical Solution

Studies of the Model

APPENDIX

Source and Scattering Probabilities

Excitation Probabilities

BIBLIOGRAPHY

\section{LIST OF FIGURES AND TABLES}

Figure

Page

1 Neutron Distributions in $\mathrm{D}_{2} \mathrm{O}$ at $80^{\circ} \mathrm{C}$ for Different Amounts of Absorption

2 Neutron Distributions in $\mathrm{D}_{2} \mathrm{O}$ at Different Moderator Temperatures

3 Neutron Distributions in $\mathrm{H}_{2} \mathrm{O}$ at $80^{\circ} \mathrm{C}$ for Different Amounts of Absorption

4 Variation of Effective Mass

5 Effect of Gaseous Moderator

6 Dependence on Vibrational Threshold

7 Vibrational Excitation Probability

Table

I Effective Neutron Temperatures

II Empirical Formula for Neutron Temperature 
NEUTRON ENERGY SPECTRA IN WATER

INTRODUCTION

A knowledge of the energy distribution of neutrons is necessary for the evaluation of the characteristics of a reactor. The effective absorption and fission cross sections of all materials that affect production, temperature coefficients of reactivity, and reactor kinetics, depend upon the spectrum. Solutions previously reported for $\mathrm{D}_{2} \mathrm{O}$ require refinement and extension to higher temperatures and moderation by $\mathrm{H}_{2} \mathrm{O}$.

This report discusses the physical model of interaction between the neutrons and the moderator molecules and describes the neutron distributions that were obtained.

\section{SUMMARY}

Energy distributions were computed in the thermal range for neutrons in equilibrium with light and heavy water moderators. The effects of moderator temperature, absorption, and chemical binding were included.

The distributions exhibit a Maxwellian-shaped region at low energy, a $1 / \mathrm{E}$ tail at high energy and an intermediate transitional region. The shapes of the spectra in the thermal region permit the definition of an effective neutron temperature, $\mathrm{T}_{\mathrm{n}}$, which is the temperature of a Maxwellian distribution fitted by least squares to the neutron distribution. The effective neutron temperature for $\mathrm{D}_{2} \mathrm{O}$ is given in terms of the moderator temperature, To, and of the ab.. sorption and scattering cross sections by the formula

$$
\mathrm{T}_{\mathrm{n}}=\mathrm{T}_{\mathrm{o}}\left[1+1.92 \frac{\Sigma_{\mathrm{a}}\left(\mathrm{T}_{\mathrm{o}}\right)}{\Sigma_{\mathrm{s}}}\right]
$$

In the $\mathrm{D}_{2} \mathrm{O}$ moderator, variations of the scattering mass over the range of possible error affect the spectrum by three per cent. Possible errors in the threshold for vibrational excitation affect the distribution by eight per cent, and the influence of the chemical binding term in the scattering cross section is less than ten per cent. 


\section{DISCUSSION}

This report extends the study of neutron distribution in heavy water, which was begun in DP-33(1). Further refinements and parametric treatments of temperature and absorption were made to test the mathematical model of the moderating process and to study the spectrum. Distributions for light water were obtained also. The results provide information necessary for the evaluation of effective cross sections in reactors and hence of reactor behavior.

PHYSICAL MODEL

The problem was approached by evaluating the thermal source and the probabilities of absorption and of detailed scattering as functions of neutron velocity. Equilibrium spectra were then obtained from the condition of conservation of neutrons. The equation of neutron balance in the range of thermal energy is

$$
S(v)+\int P\left(v, v^{\prime}\right) N\left(v^{\prime}\right) d v^{\prime}=N(v)[V(v)+\gamma(v)]
$$

The functions $S(v), V(v), \gamma(v)$, and $N(v)$ are, respectively, the source strength, scattering probability, absorption probability, and population of neutrons of velocity $v$ per unit velocity. P(v, $\left.v^{i}\right) d v$ is the probability that a neutron of velocity $\mathrm{v}^{\prime}$ will be scattered into the region $\langle v, v+d v\rangle$. The scattering cross section upon which these functions are based was obtained by an analytical fit of experimental measurements. Expressions for $S(v), P\left(v, V^{1}\right), \sigma_{S}(v)$, and $V(v)$ obtained in Reference 1 are reviewed in the Appendix. The solution of Equation 1 of a system at equilibrium $[\gamma(v)=S(v)=0]$ is the MaxwellBoltzmann distribution, $M(v)$.

The moderating atoms, being bound in molecules of water, offer more inertia to the impinging neutrons than would a gas of free hydrogen atoms. To account for this effect of chemical binding, an effective mass, $M$, is assigned at low energy to the hydrogen in the rigid molecule according to the Sachs-Teller mass tensor ${ }^{2}$. The effective mass of the deuteron in $\mathrm{D}_{2} \mathrm{O}$ is 3.6 and that of the proton in $\mathrm{H}_{2} \mathrm{O}$ is 1.9. The moderator molecules are assumed to have a Maxwel1ian distribution of velocities, $V$.

$$
M(V)=\frac{4 \beta^{3}}{\sqrt{\pi}} V^{2} e^{-\beta^{2} V^{2}}
$$

where

$$
\beta^{2}=\frac{M}{2 k T_{0}}
$$

and where $\mathrm{T}_{0}$ is the temperature of the moderator.

For neutron energies above the vibrational threshold energy, $E_{1}$, energy transfer is based on the free particle mass, since integration of excitation probabilities derived by Arley ${ }^{\prime}$ shows the 
proton to be rapidly uncoupled (See Appendix). The microscopic scattering-down probability is assumed to be independent of the moderator motion and the scattering-up probabilities are derived from the requirement of detailed balance in the equilibrium system. The thermal limit, $E_{2}$, is defined as that neutron energy above which absorption may be ignored and the spectrum may be assumed to behave as 1/E. The values $\mathrm{E}_{1}=0.226 \mathrm{ev}$ and $\mathrm{E}_{I}=0.143 \mathrm{ev}$ were assigned to $\mathrm{H}_{2} \mathrm{O}$ and $\mathrm{D}_{2} \mathrm{O}$ respectively to approximate the mean vibrational energies. A conservative choice of the thermal cut-off energy, $E_{2}=2.87 \mathrm{ev}$, placed this energy well into the $1 / \mathrm{E}$ region.

The expressions $V(v)$ and $\int_{0}^{\infty} P\left(v^{\prime}, v\right) d v^{\prime}$ both stand for

neutrons scattered from the state $v$ and hence are equal. In the form used for numerical solution, $V(v)$ becomes a vector $V_{j}$ and $P\left(v, V^{1}\right)$ becomes a matrix $P_{i j}$. The equality in the difference form,

$$
v_{j}=\Sigma_{i} P_{i j} \Delta v_{i}
$$

is maintained by adjusting the probability of scattering without energy transfer, $\mathrm{P}_{11}$.

The spectrum of a finite pile can be approximated by interpreting the leakage as additional absorption. Thus in a $1 / v-a b s o r b i n g$ system, $\gamma$ is not constant but is a function of energy.

\section{NUMERICAL SOLUTION}

When written in difference form the balance equation is

$$
\mathrm{KN}=\mathrm{N}
$$

where $K$ is a matrix with the components

$$
K_{i j}=\frac{P_{i j} \Delta v_{j}}{V_{i}+\gamma_{i}}
$$

The rank of $K_{i j}$ is increased by one to accommodate the source term.

Equation 3 was solved by successive approximation on the IBM 650. An arbitrary initial distribution converges to within 0.01 per cent of the solution in 60 iterations at the rate of 32 seconds per iteration. The convergence was accelerated by occasional manual extrapolation from successive iterations of the distribution vector. Systems with lower $\gamma$ required more frequent extrapolation.

Figures 1, 2, and 3 show typical solutions of the balance equation for infinite homogeneous $\mathrm{H}_{2} \mathrm{O}-$ and $\mathrm{D}_{2} \mathrm{O}$-moderated reactors. The absorption rate was assumed to be proportional to $1 / \mathrm{v}$ in the center-of-mass system although the computation procedure could accommodate an arbitrary function. 
Figure 1 shows the hardening effect of the absorption on a system moderated by $\mathrm{D}_{2} \mathrm{O}$ at a constant temperature of $80^{\circ} \mathrm{C}$. The distribution below 0.1 ev retains the Maxwellian shape with a shift toward higher energy as absorption increases. Above $0.1 \mathrm{ev}$, there is a transitional region which connects to the $1 / \mathrm{E}$ tail near $0.5 \mathrm{ev}$.

The Maxwellian portion of the distribution suggests the definition of an effective neutron temperature, $\mathrm{T}_{n}$, as the temperature of a true Maxwellian distribution fitted to the computed thermal flux by the method of least squares. An expression of the form proposed by Karl Cohen 4

$$
\mathrm{T}_{n}=\mathrm{T}_{0}\left[1+\mathrm{A} \frac{\Sigma_{\mathrm{a}}\left(\mathrm{T}_{\mathrm{o}}\right)}{\Sigma_{\mathrm{S}}}\right]
$$

where

$$
A=1.92
$$

gives the effective temperature within one per cent of the calculated distributions in the range $0 \leq \frac{\Sigma_{a}\left(T_{0}\right)}{\Sigma_{s}} \leq 0.25$ for $D_{2} O$-moderated

systems. To is the temperature of the moderator and $\Sigma_{\mathbf{a}}$ and $\Sigma_{\mathrm{s}}$ are the absorption and scattering cross sections of the system.

E. R. Cohen (4) obtained distributions corresponding to $A=$ 1.65 by analytical approximation; and Coveyou, Bate, and Osborn
obtained $\mathrm{A}=1.81$ by a Monte Carlo method. The coefficient $\mathrm{A}$ for $\mathrm{H}_{2} \mathrm{O}$ shows strong variations with temperature and absorption as shown in Table II. Table I gives effective neutron temperatures of both $\mathrm{D}_{2} \mathrm{O}-$ and $\mathrm{H}_{2} \mathrm{O}$-moderated systems for a variety of temperatures and absorption cross sections.

STUDIES OF THE MODEL

The influence of chemical binding in energy transfer was found by computing distributions of a typical system $\left(\Sigma_{2}=0.0111 \mathrm{~cm}^{-1}\right.$, $\mathrm{kT}=0.0304 \mathrm{ev}$ ) with effective moderator masses of two and five. Figure 4 shows that the deviations of these spectra from the spectrum of actual effective mass, 3.6, are less than five per cent. The discontinuity of the scattering mass at the vibrational threshold is evidenced at $0.148 \mathrm{ev}$ in the figure. Slight hardening of the spectrum with heavier targets is indicated.

Chemical binding also affects the scattering cross section at low energies. Several distributions were obtained under the assumption that the moderator was a molecular gas. The distortion of the spectrum is small in systems of low absorption, but increases with $\gamma$ as shown in Figure 5. The reduced scattering of the gaseous moderator at low energy attenuates the spectrum in that region by as much as ten per cent for $\gamma=0.2$. 
The spectra of a $\mathrm{D}_{2} \mathrm{O}$ moderator computed with vibrational thresholds of $0.09 \mathrm{ev}$ and $0.23 \mathrm{ev}$ deviate from the distribution of the adopted $0.143 \mathrm{ev}$ as shown in Figure 6 . Since vibrational effects are approximated in the model, these deviations indicate the magnitude of possible error. $D_{2} \mathrm{O}$ possesses three modes of vibration with thresholds lying at $0.075 \mathrm{ev}, 0.171 \mathrm{ev}$, and $0.179 \mathrm{ev}$ and the deuteron is not entirely uncoupled above threshold energy. The spectrum derived with the assumption of total decomposition at $0.143 \mathrm{ev}$ deviates less than eight per cent from the true spectrum.

The effective cross section $\bar{\Sigma}$ of a nuclide which is exposed to a flux of neutrons of different energies is proportional to the Integral of the density of events in the increment dv.

$$
\bar{\Sigma}=\frac{1}{\Phi} \int N(v) v \sigma(v) d v
$$

Thus $\bar{\Sigma}$ depends on the spectrum and is a function of absorption and scattering probabilities and moderator composition. Effective cross sections and cadmium ratios can be computed for isotopes of interest. Tables may be prepared for the comparison of experiments made in piles operating under different conditions, and for the calculation of reactor production and operating characteristics.

H. D. Brown

H. D. Brown

Theoretical Physics Division 


\section{APPENDIX}

SOURCE AND SCATTERING PROBABILITIES

Analytic expressions for the various components of the balance Equation 1 were derived in Reference 1.

ly by the formula

The scattering cross section of hydrogen is fitted adequate-

$$
\sigma_{S}(r)=A+B e^{-K r^{2}}
$$

where $r$ is the relative velocity of the neutron and the moderator atom.

For protons in $\mathrm{H}_{2} \mathrm{O}, \mathrm{A}=20.7, \mathrm{~B}=13.1$, and $\mathrm{K}=4.5$

and for deuterons in $\mathrm{D}_{2} \mathrm{O}, \mathrm{A}=3.3, \mathrm{~B}=1.6$, and $\mathrm{K}=2.88$

is

The probability of scattering from the state of velocity $v$

$$
\begin{aligned}
V(v) & =\int_{0}^{\infty} \sigma_{S}(r) r M(V) d^{3} V \\
& =\frac{A}{\beta}\left\{\frac{e^{-\beta^{2} v^{2}}}{\sqrt{\pi}}+\left(\frac{1}{2 \beta v}+\beta v\right) \operatorname{Erf}(\beta v)\right\} \\
& +\frac{B}{\beta}\left\{\frac{\tau^{4} e^{-\beta^{2} v^{2}}}{\sqrt{\pi}}+\tau^{4}\left(\frac{1}{2 \beta \tau v}+\beta \tau v\right) \operatorname{Erf}(\beta \tau v) e^{-K \tau^{2} v^{2}}\right\}
\end{aligned}
$$

where $\tau^{2}=\frac{\beta^{2}}{\beta^{2}+K}$ and $\operatorname{Erf}(x)=\frac{2}{\sqrt{\pi}} \cdot \int_{0}^{x} e^{-y^{2} d y}$

Simllarly the probability of scattering from velocity $v^{\prime}$ to velocity $v$ is

$$
P\left(v, v^{\prime}\right)=\int_{0}^{\infty} \sigma_{S}(r) r M(V) d^{3} V p\left(v, v^{\prime} ; \vec{V}\right)
$$

The detailed probability of scattering from $v^{\prime}$ to $v$ upon collision with a target of velocity $\vec{V}$ is

$$
\mathrm{p}\left(\mathrm{v}, \mathrm{v}^{\prime} ; \overrightarrow{\mathrm{V}}\right)=\frac{2 \mathrm{v}}{\mathrm{v}_{\max }^{2}-\mathrm{v}_{\min }^{2}}
$$

In the interval $v_{\min } \leq \mathrm{v} \leq \mathrm{v}_{\max }$ and is zero elsewhere. The velocities $v_{\min }$ and $v_{\max }$ are related by simple elastic scattering to the velocity of the center of mass, $v_{c}$, and the relative velocity. 


$$
\begin{aligned}
& v_{\text {max }}=v_{c}+\frac{M}{M+I} r \\
& v_{\text {min }}=v_{c}-\frac{M}{M+1} r
\end{aligned}
$$

Below energy $E_{1}, P\left(v, v^{\prime}\right)$ has the form

$$
\begin{aligned}
& P\left(v, v^{\prime}\right)=A \frac{(M+1)^{2}}{\beta^{2}} \frac{v}{v^{\prime}}\left\{\operatorname{Erf}\left(\beta \theta v \mp \beta \xi v^{\prime}\right) \mp \operatorname{Erf}\left(\beta \theta v \pm \beta \xi v^{\prime}\right)\right. \\
& \left.+e^{\frac{\beta^{2}}{M}\left(v^{2}-v^{2}\right)}\left[\operatorname{Erf}\left(\beta \theta v^{\prime} \pm \beta \xi v\right)-\operatorname{Erf}\left(\beta \xi v \mp \beta \theta v^{\prime}\right)\right]\right] \\
& +B \frac{(M+1)^{2}}{4 M} \frac{\beta^{3}}{\sqrt{\beta^{2}+K}}\left[\beta^{2}+K(M+1)\right]^{-1} \frac{v}{V} \mid e^{-\frac{K \beta^{2} v^{2}}{\beta^{2}+K}} \cdot \\
& \text { - }\left[\operatorname{Erf}\left(\beta \theta^{\prime} v \mp \beta \xi^{\prime} v^{\prime}\right) \mp \operatorname{Erf}\left(\beta \theta^{\prime} v \pm \beta \xi^{\prime} v^{\prime}\right)\right] \\
& \left.+e^{\frac{\beta^{2}}{M}}\left[v^{\prime 2}-\frac{\beta^{2}+K(M+1)}{\beta^{2}+K} v^{2}\right]\left[\operatorname{Erf}\left(\beta \theta^{\prime} v^{\prime} \pm \beta \xi^{\prime} v\right)-\operatorname{Erf}\left(\beta \xi^{\prime} v \mp \beta \theta^{\prime} v^{\prime}\right)\right]\right\}
\end{aligned}
$$

where the upper sign is taken for $\mathrm{v} \geq \mathrm{V}^{\prime}$.

$\theta=\frac{M+1}{2 M}, \xi=\frac{M-1}{2 M}, \theta^{\prime}=\theta \sqrt{1+\frac{K}{\beta^{2}}}, \xi^{\prime}=\xi\left(1+\frac{K}{\beta^{2}}\right)^{-\frac{1}{2}}-\theta K\left(\beta \sqrt{\beta^{2}+K}\right)^{-1}$

In the energy interval $\left\langle E_{1}, E_{2}\right\rangle$ the neutron velocity is great compared to the target velocity so that the motion of the moderator
may be ignored in slowing down. The detailed scattering reduces to

$$
\mathrm{p}\left(\mathrm{v}, \mathrm{v}^{\prime} ; \overrightarrow{\mathrm{V}}\right)=\left\{\begin{array}{cc}
\frac{2 \mathrm{v}}{\mathrm{v}^{2}\left(I-\alpha^{2}\right)} & \text { when } \alpha v^{\prime} \leq \mathrm{v} \leq \mathrm{v}^{\prime} \\
0 & \text { otherwise }
\end{array}\right.
$$

where $\alpha=\frac{M-1}{M+1}$

so that $\quad P\left(v, v^{\prime}\right)=\left\{\begin{array}{cl}\frac{2 v}{v^{\prime 2}\left(1-\alpha^{2}\right)} V^{\left(v^{\prime}\right)} & \text { when } \alpha v^{\prime} \leq v \leq v^{\prime} \\ 0 & \text { when } v \leq \alpha v^{\prime}\end{array}\right.$

The probability of scattering with increase of energy in this region is obtained from the detailed balance of the equilibrium system

$$
M\left(v^{\prime}\right) P\left(v, v^{\prime}\right)=M(v) P\left(v^{\prime}, v\right)
$$

The source function $\mathrm{S}(\mathrm{v})$ introduces neutrons scattered from above the thermal limit $E_{2}$ into the thermal range. 


$$
S(v)=\int_{v_{2}}^{\frac{v}{\alpha}} \sigma_{S^{\prime}} v^{\prime} N\left(v^{\prime}\right) d v^{\prime} p\left(v, v^{\prime} ; \vec{V}\right)
$$

In the region above $E_{2}, p\left(v, v^{\prime} ; \vec{V}\right)$ is again independent of $\vec{V}, \sigma_{S}$ is constant, and $\mathrm{N}(\mathrm{E})=\mathrm{A} / \mathrm{E}$.

$$
S(v)=\left\{\begin{array}{cl}
0 & \text { when } v<\alpha v_{2} \\
\frac{A \sigma_{S} v}{I-\alpha^{2}}\left(\frac{1}{E_{2}}-\frac{\alpha^{2}}{E}\right) & \text { when } \alpha v_{2} \leq v \leq v_{2}
\end{array}\right.
$$

The probability of neutron absorption is

$$
\gamma(v)=\int_{0}^{\infty} \sigma_{a}(r) r M(V) d^{3} V
$$

When dealing with a $1 / r$ absorber,

$$
\gamma=\text { constant }=\frac{\Sigma_{\mathrm{a}}^{\mathrm{eff}}(\overline{\mathrm{v}}) \overline{\mathrm{v}}}{\mathrm{N}_{\mathrm{H}}}
$$

where $\mathrm{N}_{\mathrm{H}}$ is the hydrogen density. A $\gamma$ of 0.0426 corresponds to an effective absorption cross section of $0.0111 \mathrm{~cm}^{-1}$ at 2200 meters per second.

\section{EXCITATION PROBABILITIES}

The rate at which the proton is effectively uncoupled from the water molecule as the neutron energy increases above the vibrational threshold is estimated from the relative transition probabilities for the first and second modes of vibration. $N$. Arley has derived the differential cross sectifon per unit solid angle, $I_{m n}$, for the isotropic harmonic oscillator ${ }^{3}$. The ratio

$$
f=\int I_{01} d \Omega / \int I_{00} d \Omega
$$

is the number of neutrons exciting the first vibrational level relative to those experiencing elastic scattering. Using the Born approximation, Arley obtains

$$
I_{\text {on }}(\theta)=\frac{k_{o n}}{k_{0}} \frac{1}{n !} x^{n} e^{-x}
$$

where $\vec{k}_{\mathrm{O}}, \vec{k}_{\mathrm{O}}$ are the wave vectors of the neutron before and after collision and

$$
x=\frac{E}{\hbar \omega}\left[2-\frac{\hbar \omega}{E}-2\left(1-\frac{\hbar \omega}{E}\right)^{\frac{1}{2}} \cos \theta\right]
$$


The ratio $\frac{E}{\hbar \omega}$ is the incident energy of the neutron in units of the energy quantum of the oscillator. Integrating the terms of the relative excitation over the solid angle, one obtains

$f=\left(1-\frac{\hbar \omega}{E}\right)^{\frac{1}{2}}\left[\left(2 \frac{E}{\hbar \omega}-1\right)+1+2 \sqrt{\frac{E}{\hbar \omega}\left(\frac{E}{\hbar \omega}-1\right)} \operatorname{coth}\left(-2 \sqrt{\frac{E}{\hbar \omega}\left(\frac{E}{\hbar \omega}-1\right)}\right]\right.$

The ratio $f$ is graphed as a function of $\frac{E}{\hbar \omega}$ in Figure 7 . By the time the neutron energy exceeds the threshold by 50 per cent, three times as many neutrons excite the first mode as experience elastic scattering. It is assumed that higher modes are also rapidly excited for neutron energies exceeding the threshold and that the deuteron is effectively unbound.

This simplified model provides the basis for treating energy transfer as if the deuteron were free at neutron energies above the threshold and fully bound below 1 t.

\section{BIBLIOGRAPHY}

1. Brown, H. D. and St. John, D. S. Neutron Energy Spectra in $\mathrm{D}_{2} \mathrm{O}$. E. I. du Pont de Nemours \& Company, DP-33, February 1954 (Declassified).

2. Sachs, R. G. and Teller, E. "The Scattering of Slow Neutrons by Molecular Gases." Phys. Rev. 60, 18-27 (1941).

3. Arley, Niels on the Scattering of Thermal Neutrons by Bound Protons. Det. Kgl. Danske V1denskabernes Selskab (1938).

4. Cohen, E. R. North American Aviation, Inc., NAA-SR-1127, February 1955 (Classified report).

5. Coveyou, R. R., Bate, R. R., and Osborn, R. K. Effect of Moderator Temperature Upon Neutron Flux in Infinite, Capturing Medium. Oak Ridge National Laboratory, ORNL-1958. october 1955. 


\section{TABLE I}

EFFECTIVE NEUTRON TEMPERATURES

$$
\begin{aligned}
& \mathrm{kT}_{\mathrm{n}}(\mathrm{ev}) \text { for } \mathrm{D}_{2} \mathrm{O} \\
& \Sigma_{\mathrm{a}}(0.0257 \mathrm{ev})
\end{aligned}
$$

$k \mathrm{~T}$

0.0111

0.0257

0.0279

0.0377

0.035
0.040

0.0429

$$
\frac{\mathrm{kT}_{\mathrm{n}} \text { (ev) for } \mathrm{H}_{2} \mathrm{O}}{\Sigma_{\mathrm{a}}(0.0257 \mathrm{ev})}
$$
$k T_{0}$
0.026
0.052
0.104
0.260
0.520

0.0257

0.0261

0.0266

0.0273

0.0312

0.0320

0.0357

0.0365

0.0407

0.0414

0.0296

0.0341

0.0385

-...

0.0432

0.0331

0.0372

0.0413

0.0458

The effective neutron temperature in electron volts, $k \mathrm{~T}_{n}$, is tabulated as a function of the moderator temperature, $\mathrm{kT}_{0}$, and the effective absorption cross section of the system at room temperature, $\Sigma_{a}(0.0257$ $\mathrm{ev}$ ) in $\mathrm{cm}^{-1}$. 
TABLE II

EMPIRICAL FORMULA FOR NEUTRON TEMPERATURE

A for $\mathrm{D}_{2} \mathrm{O}$

$\Sigma_{\mathrm{a}}(0.0257 \mathrm{ev})$
$k \mathrm{~T}_{\mathrm{O}}$
$0.011,1$
0.0167
0.0260
0.0520

0.0257
0.0304
0.035
0.040

1.80

1.80

1.96

1.90

1.87

1.92

1.89

1.88

.00

1.89

1.88

1.98

1.99

2.00

$2.05 \overline{\mathrm{A}}=1.92$

A for $\mathrm{H}_{2} \mathrm{O}$

\begin{tabular}{lrrrrr} 
& \multicolumn{5}{c}{$\Sigma_{\mathrm{a}}(0.0257 \mathrm{ev})$} \\
$\mathrm{KT}_{0}$ & 0.026 & 0.052 & 0.104 & 0.260 & 0.520 \\
0.0257 & & & & & \\
0.0304 & 0.876 & 0.985 & 0.876 & 0.854 & 0.810 \\
0.035 & 0.805 & 0.805 & 0.805 & 0.745 & 0.685 \\
0.040 & $-\ldots-$ & 0.657 & 0.704 & 0.657 & 0.591 \\
&.- & 0.614 & 0.614 & 0.562 & 0.509
\end{tabular}

The effective neutron temperatures of $\mathrm{D}_{2} \mathrm{O}$ systems satisfy the formula

$$
\mathrm{T}_{\mathrm{n}}=\mathrm{T}_{\mathrm{o}}\left[1+\mathrm{A} \frac{\Sigma_{\mathrm{a}}\left(\mathrm{T}_{\mathrm{o}}\right)}{\Sigma_{\mathrm{S}}}\right]
$$

where A $1 \mathrm{~s}$ tabulated above. The mean value, $A=1.92$ fits the derived temperatures within one per cent. The parameter A is not constant for $\mathrm{H}_{2} \mathrm{O}$ systems but decreases for harder spectra as shown in the lower table. 


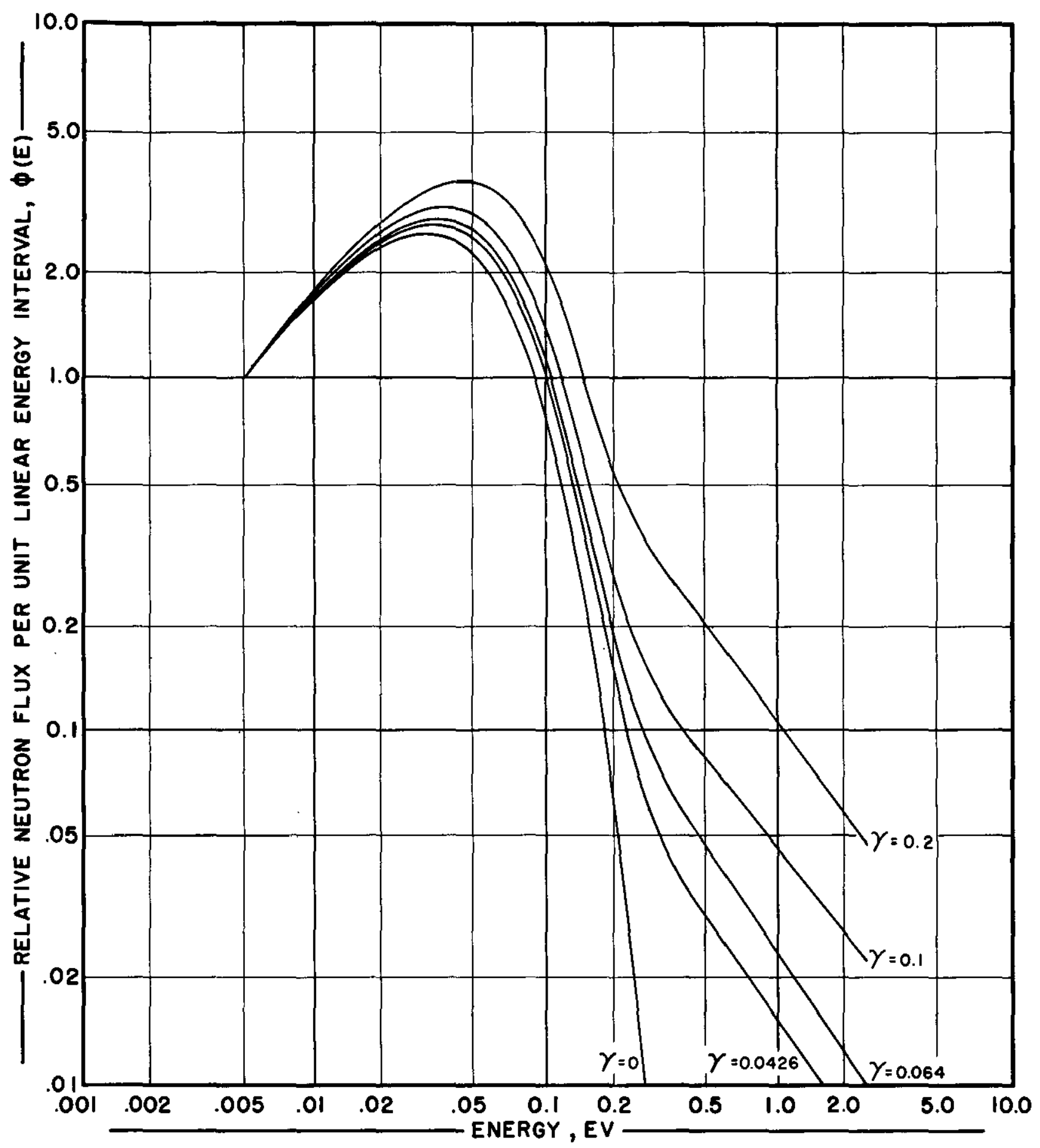

NEUTRON DISTRIBUTIONS IN D 20 AT $80^{\circ} \mathrm{C}$ FOR DIFFERENT AMOUNTS OF ABSORPTION

ALL NEUTRON SPECTRA ARE SHOWN FOR A MODERATOR TEMPERATURE OF $80^{\circ} \mathrm{C}$. THE CURVES ARE MADE TO INTERSECT AT 0.005 EV TO SHOW THE HARDENING OF THE DISTRIBUTIONS WITH INCREASING ABSORPTION. THE PARAMETER $\gamma$ IS PROPORTIONAL TO THE EFFECTIVE ABSORPTION CROSS SECTION. $Y=3.823 \sum_{\mathrm{a}}^{\mathrm{eff}}$ 


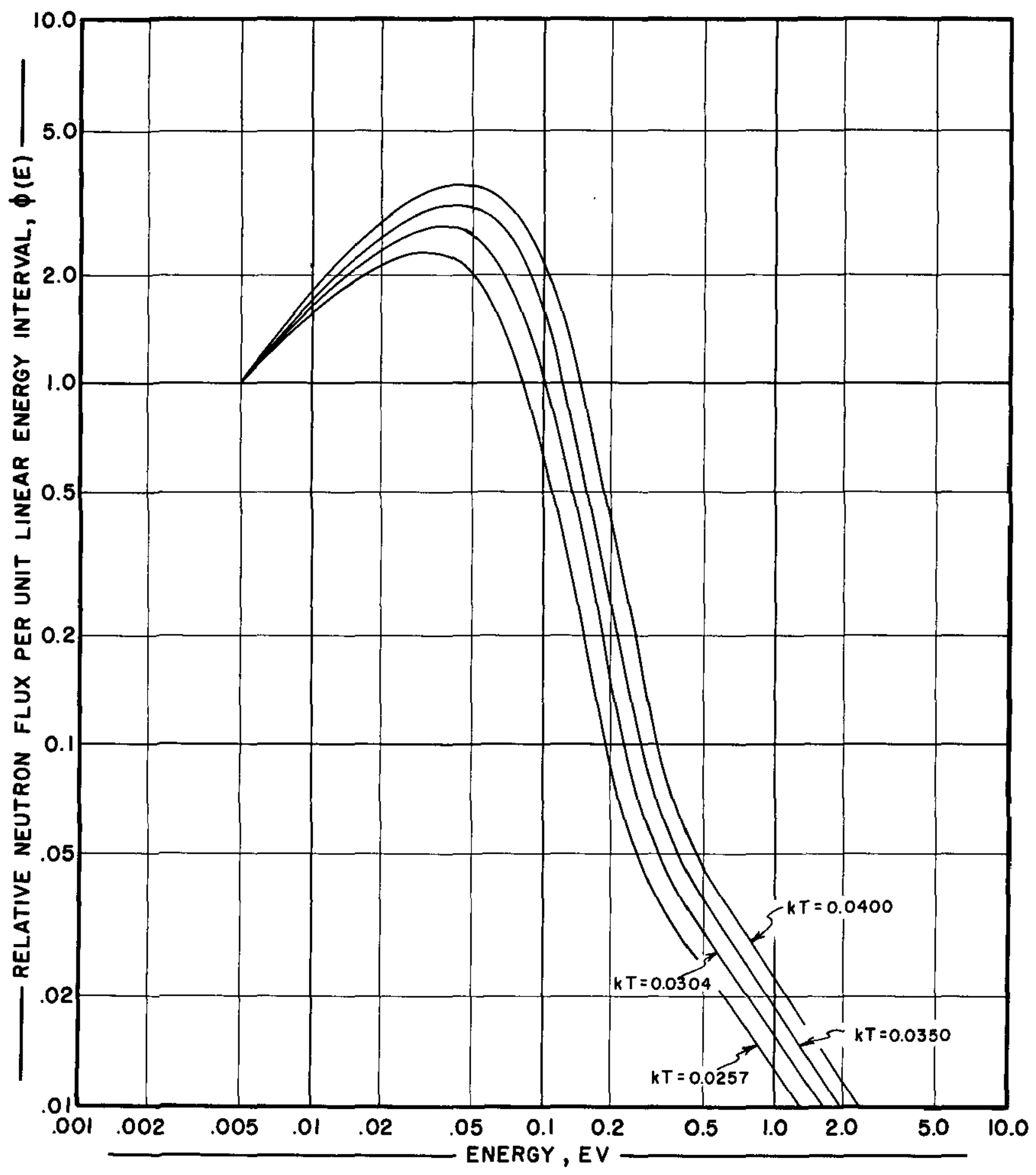

\section{NEUTRON DISTRIBUTIONS IN $\mathrm{D}_{2}$ O AT DIFFERENT MODERATOR TEMPERATURES}

ALL NEUTRON SPECTRA ARE SHOWN FOR AN EFFECTIVE AGSORPTION CROSS SECTION OF O.OIII CM-I THE DISTRIBUTION HARDENS WITH INCREASING TEMPERATURE BUT DOES NOT CHANGE SHAPE, IN CONTRAST TO THE ABSORPTION HARDENING SHOWN IN FIGURE I. 


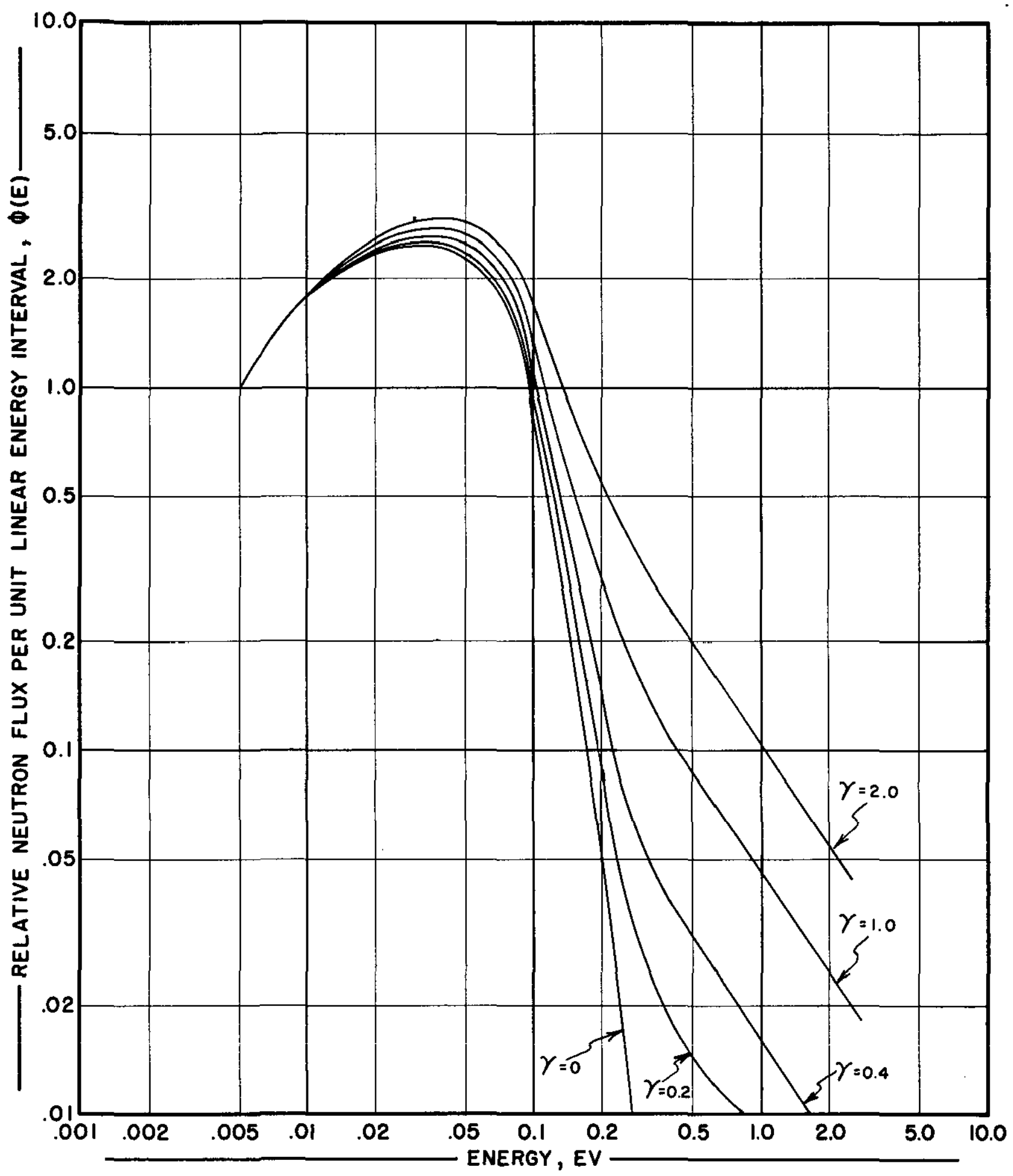

NEUTRON DISTRIBUTIONS IN $\mathrm{H}_{2} \mathrm{O}$ AT $80^{\circ} \mathrm{C}$ FOR DIFFERENT AMOUNTS OF ABSORPTION

THE DISTRIBUTIONS ARE CALCULATED FOR A MODERATOR TEMPERATURE OF $80^{\circ} \mathrm{C}$. THE SPECTRA ARE MUCH SOFTER THAN THOSE OF $D_{2} O$ IN CONSEQUENCE OF THE INCREASED SLOWING-DOWN POWER. 


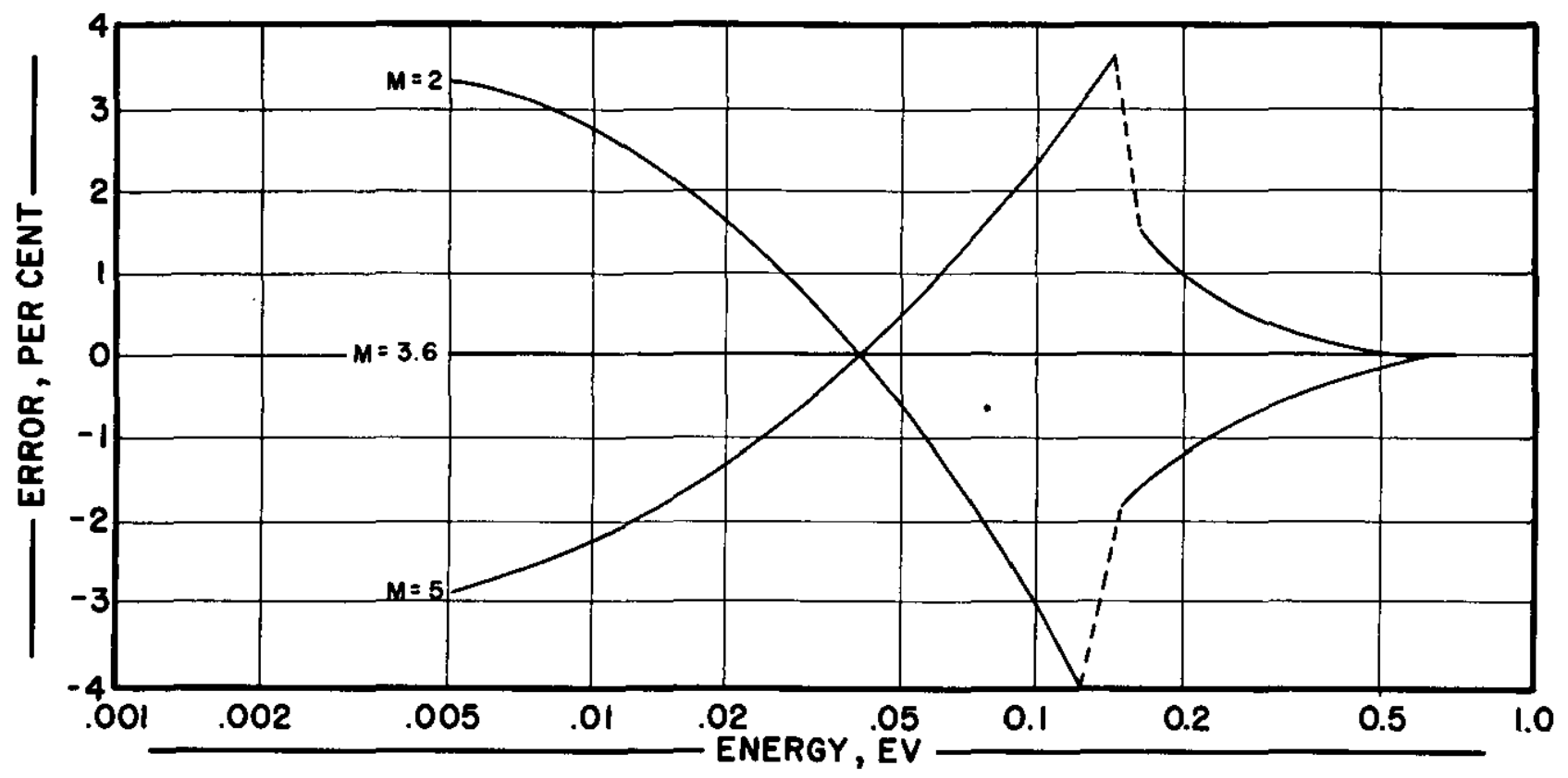

\section{VARIATION OF EFFECTIVE MASS}

DISTRIBUTIONS COMPUTED WITH EFFECTIVE MASSES OF TWO AND FIVE DEVIATE FROM THE MODEL $(M=3.6)$ BY THE AMOUNT SHOWN IN THE FIGURE. THE DISCONTINUITY AT E REFLECTS THE UNCOUPLING OF THE MODERATOR MOLECULE. THE DISTRIBUTIONS ARE NORMALIZED IN THE I/E REGION. $\sum_{\mathrm{a}}=$ $0.0111 \mathrm{CM}^{-1} . K T=0.0304 \mathrm{EV} . \mathrm{D}_{2} \mathrm{O}$ MODERATOR

\section{FIGURE 5}

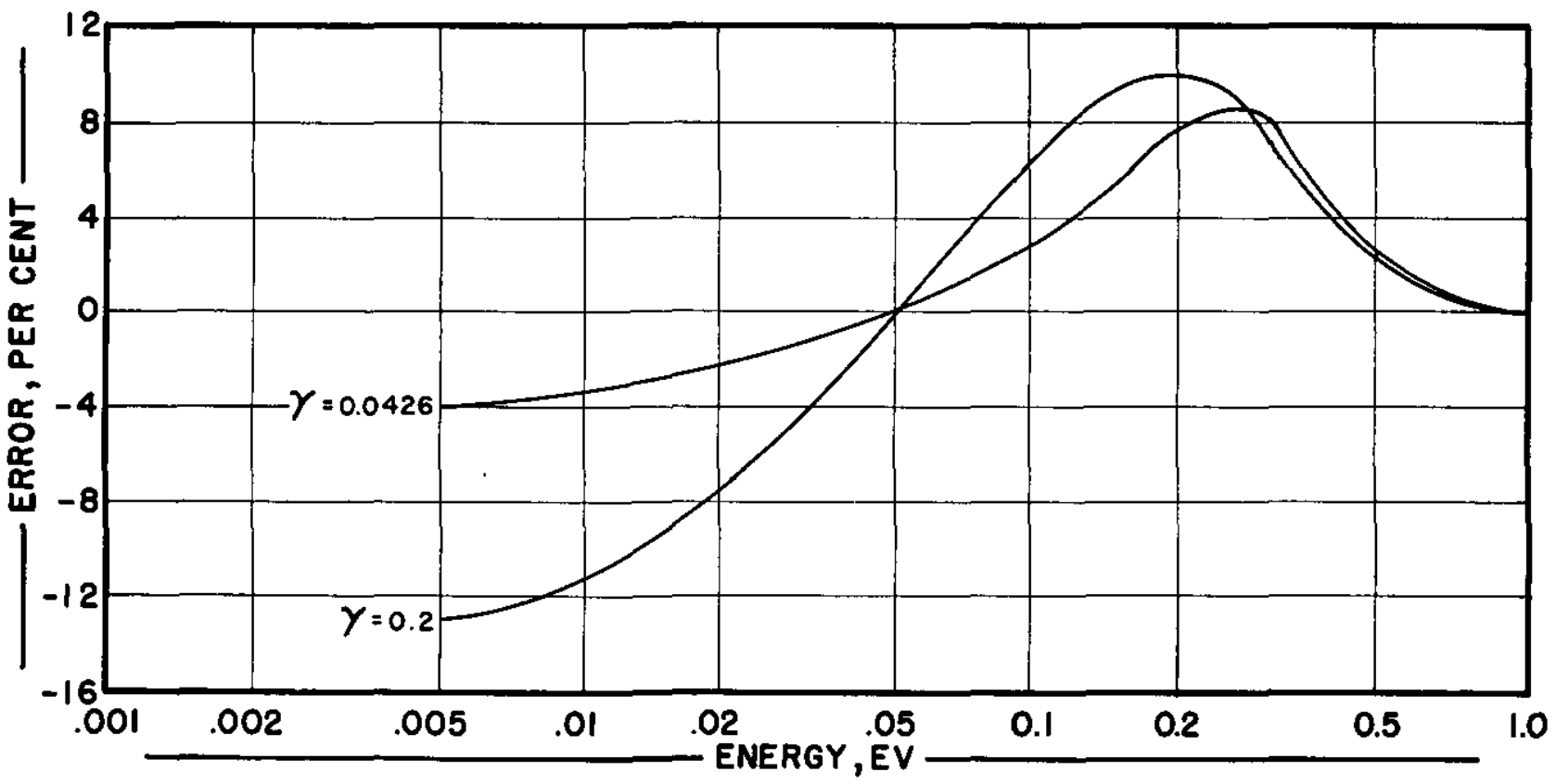

\section{EFFECT OF GASEOUS MODERATOR}

DISTRIBUTIONS COMPUTED UNDER THE ASSUMPTION OF CONSTANT DEUTERON SCATTERING CROSS SECTION IN THE RELATIVE FRAME DEVIATE FROM THE ACTUAL SYSTEM AS SHOWN. THE DISTRIBUTIONS ARE NORMALIZED IN THE I/E REGION. $K T=0.0304$ EV. D 0 MODERATOR. 


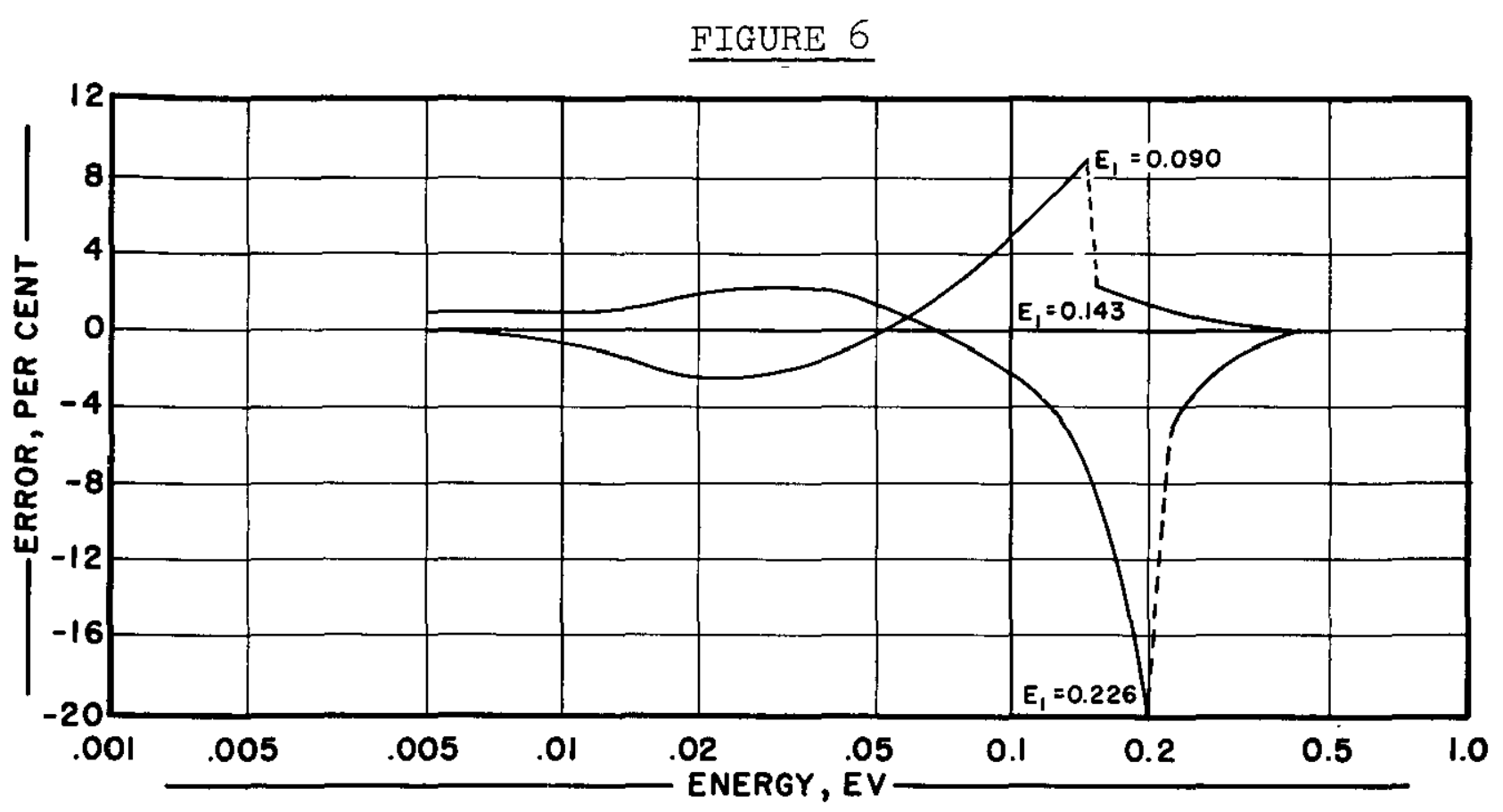

DEPENDENCE ON VIBRATIONAL THRESHOLD

DISTRIBUTIONS COMPUTED WITH THRESHOLDS OF 0.090 EV AND 0.226 EV DEVIATE FROM THE MODEL $\left(E_{1}=0.143\right.$ EV) AS SHOWN IN THE FIGURE. THE OISTRIBUTIONS ARE NORMALIZED IN THE I/E REGION. $\Sigma_{0}=0.0111 \mathrm{CM}^{-1} . K T=0.0304 \mathrm{EV} . \mathrm{D}_{2} \mathrm{O}$ MODERATOR.

\section{FIGURE 7}

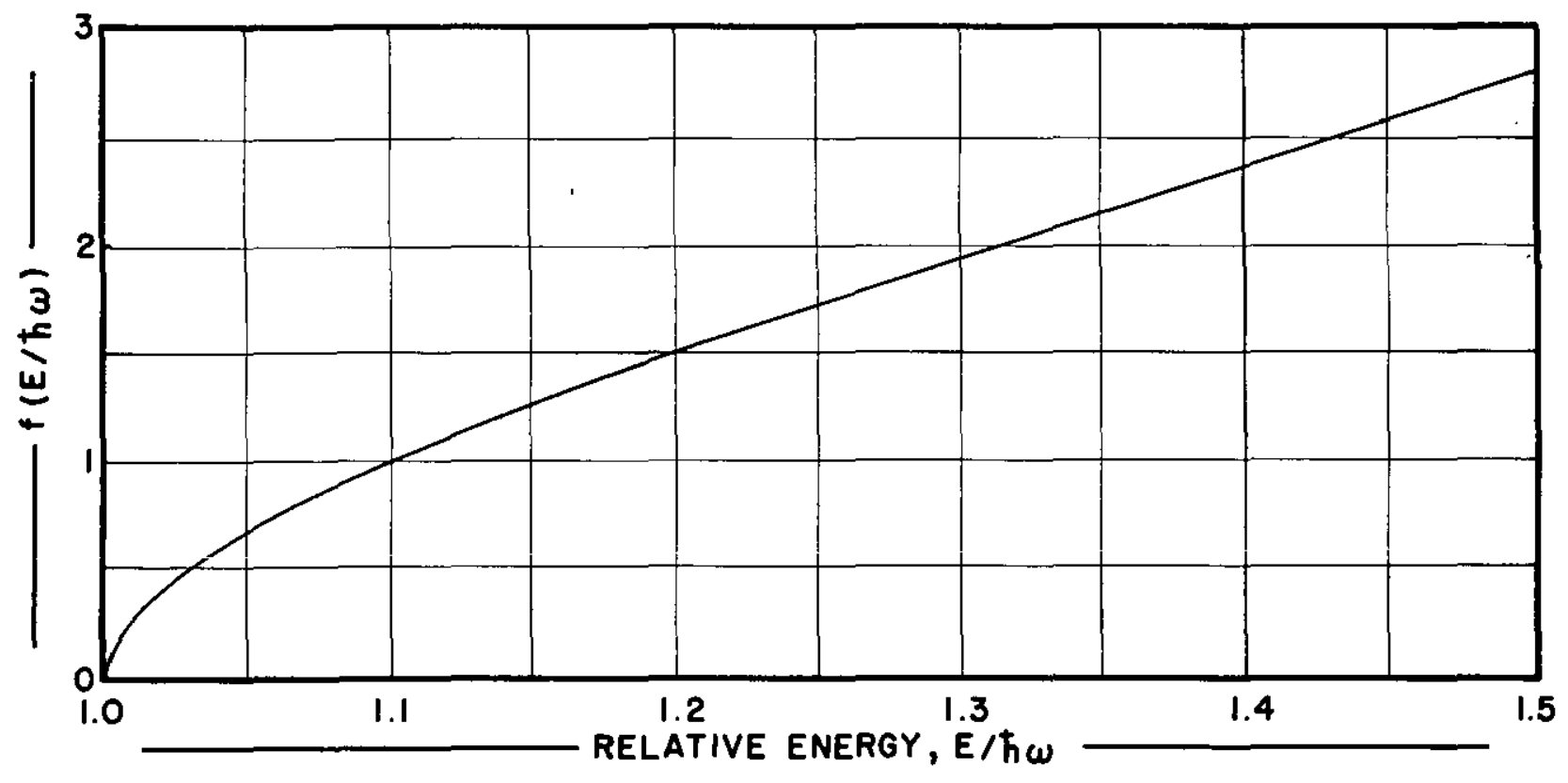

\section{VIBRATIONAL EXCITATION PROBABILITY}

f IS THE NUMBER OF NEUTRONS EXCITING THE FIRST VIBRATIONAL LEVEL RELATIVE TO THOSE EXPERIENCING ELASTIC SCATTERING. AS THE NEUTRON ENERGY INCREASES ABOVE THRESHOLD, THE VIBRATIONAL EXCITATIONS RAPIDLY BECOME THE PREFERRED MODE OF ENERGY TRANSFER. 